\title{
Research on the Reform of Master's Professional Practice Teaching in Primary Education with the Guidance of "Advanced Ability"
}

\author{
Jun Yang ${ }^{1, a}$, Yuyang $Z u^{2, b}$ \\ ${ }^{1}$ School of Education and Sports, Bohai University, Jinzhou, 121013, China \\ ${ }^{2}$ College of Foreign Languages, Bohai University, Jinzhou, 121013, China \\ a444530141@qq.com, b1143119122@qq.com
}

Keywords: Advanced ability; primary school education; master's degree; practical teaching; reform

\begin{abstract}
With "advanced ability" as the guide, the reconstruction of the primary school education professional ability to cultivate the connotation, focusing on the completion of different stages to cultivate "ability as the most important" and primary school education master professional practice ability; building "plate type" primary school education master professional practice ability training program, based on general education, and wide-caliber professional education as the basic principle, combined with the full credit system of multi-level curriculum system; set up "action research" as the main method, and gradually form the ability to enhance the practice of education; the university, primary and middle schools "seamless docking" partnership. The results show that the research method of this paper is scientific, the design concept is advanced, and the practical teaching system is comprehensive and operable. It can make the practicality of primary education curriculum and the variability of environmental development diversified, and promote the ability of primary school teachers as an important role.
\end{abstract}

\section{Introduction}

Improving the practical ability of students has become the focus and difficulty of teaching development in colleges and universities. For the cultivation of primary school teachers, the value of educational practice is irreplaceable. As some scholars have pointed out, "the understanding of education, only in the rich, realistic education practice can really get." [1] Actively strengthen the practice of teaching, carry out practical teaching reform, explore the primary school education masters professional ability training methods and measures, attention to highlight the practical ability of students, that is, with the basic skills of professional skills, social adaptability, learning development ability and innovation ability. In view of the difficult problem of college students' employment, how to improve students' practical ability, combined with our school's teaching reform and practice, to explore and try to reform unreasonable talent training mode, social needs and employment-oriented, cultivate the practical ability system, and actively promote the cultivation of innovative talents. It is of great significance to correctly understand and focus on the practice teaching mode of primary school education, which is of great significance to the development of practical teaching of primary education in universities and the establishment of professional curriculum system.

\section{Basic Idea of Master's Reform in Primary Education}

After many years masters of professional education and primary school education professional reform practice, we will locate primary school education master's reform concept as: "Enough theory, key practice, wide cultivation, fundamental accomplishment."

"Theory enough"-- broadly speaking, the "theory enough" principle should refer to the teacher education professional pre-school education stage and the content should be followed the universal provisions. It should include the requirements of general education curriculum content, professional course content, educational theory course content, science and humanities curriculum content and so on. In fact, "theoretical enough" is a basic principle of the pre-service teacher's pre-service 
education curriculum system and the choice of course content. It is a basic requirement for the knowledge of the students during the pre-service education period.

"Key practice" -- "key practice" refers to the teacher education professional training students for basic education and curriculum reform under the actual situation, through a certain period of time teaching and become qualified basic education teaching "master", not a "novice". This requires a pre-service teacher in education stage, students of basic education curriculum objectives, curriculum content, change of teaching methods with a real understanding and in-depth understanding of the "field diagnosis teaching" as the guide, and actively improve their knowledge structure, to enhance their own teaching ability.

"Wide cultivation" -- "wide cultivation " is the combination of case teaching and situational teaching, and the formation of the teaching model. In this model, set the real situation for students, and autonomy, cooperation, inquiry as the core of teaching activities, mobilize all the information resources in the teaching activities, stimulate students' all the ability to perceive the pursuit of the overall development of all aspects of the quality of our students. Our basic idea: highlight the primary school education masters teaching case, scene, situationality, diagnostic, part of the practice class from the university classroom down to primary and middle school classroom teaching activities.

"Fundamental accomplishment"-- "fundamental accomplishment" means that any education is directed at human development, its ultimate goal is to "make man into man", no matter what the cultivation of professional talent is, we can not be separated from the fundamental purpose of education. In the real graduate professional education, we have also cultivated "knowledge without culture", "capable without cultivation", "fashion but no taste" of graduate students. Teacher education is to cultivate the "human soul engineer", but also in the "accomplishment" in effort, or "teacher" is just a empty slogan [2].

\section{Basic Framework of Practical Ability Training in the Construction of Primary School Education Master's "Advanced Ability"}

The framework of the "advanced" educational model generally follows six design steps, namely, the analysis of the current economic situation and forms of education - the investigation and analysis of the talent market - the analysis of professional competence (DACUM curriculum development process) - teaching analysis - teaching design and development - teaching practice teaching evaluation. [3] Based on the analysis and reference, combined with the characteristics of the master's degree in higher primary education, the basic framework of the advanced educational model of primary education majors' ability is preliminarily designed by consulting experts. (Fig.1)

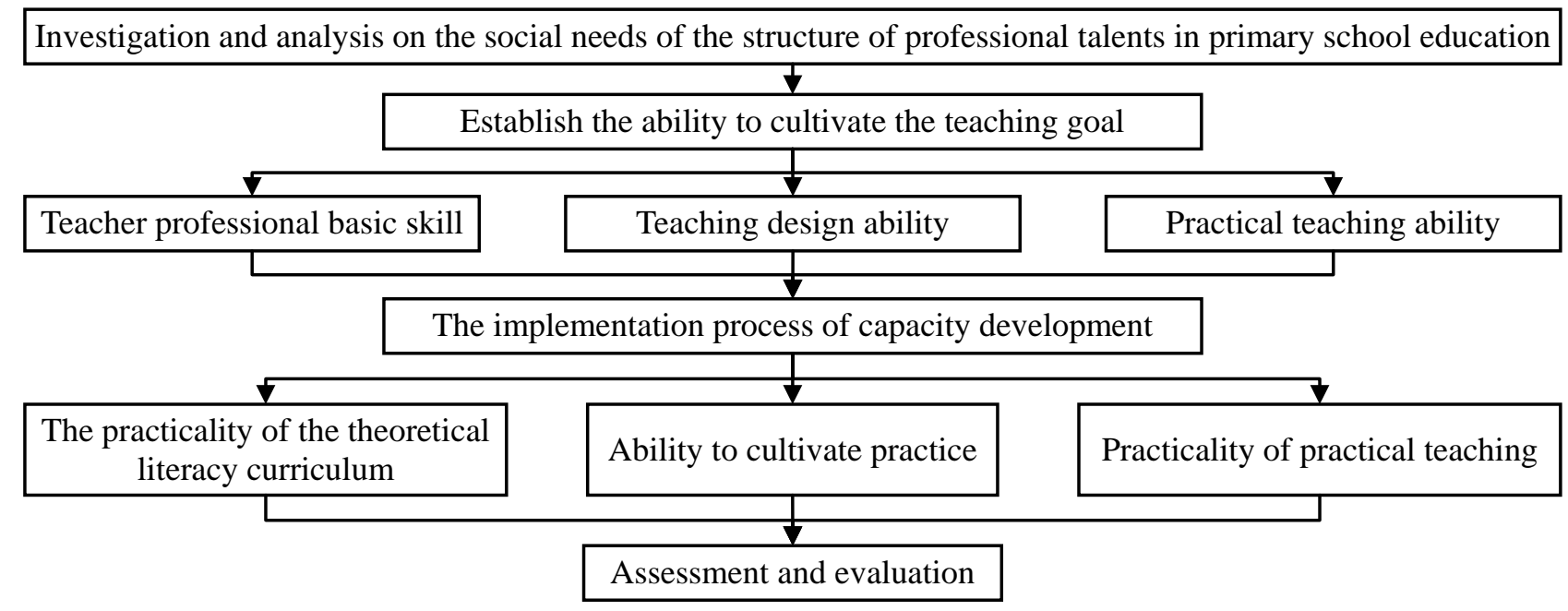

Fig.1. The basic framework of the educational model of "advanced education" in primary school education masters 


\section{Curriculum System and Training}

\section{(1) Curriculum system "modular"}

Primary school education major degree to common class, professional basic courses, professional core courses, professional elective courses, practical teaching link and other aspects of the composition. In the elective module, we set different growth platforms and course modules for different types of students. Education psychology module, primary school mathematics module, primary school Chinese module, primary science module, education management module, teacher growth module, focus on cultivating its teaching, management and research ability. [4]

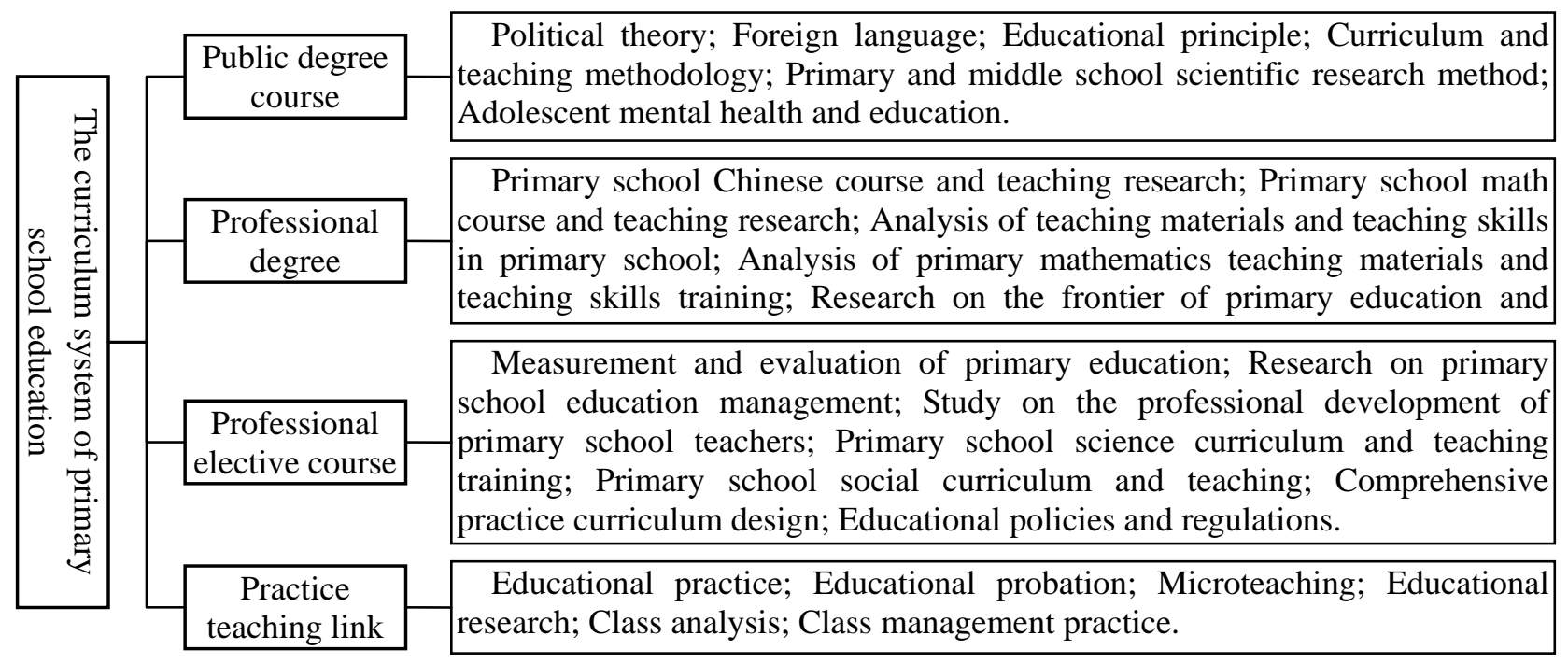

Fig.2. The Curriculum System of Master's Degree in Primary School Education

(2) Ability to cultivate "full"

In school, at the core of the course, we set up the curriculum of "primary school science curriculum and teaching theory", "primary school language curriculum and teaching theory", "primary school mathematics course and teaching theory", and set up various courses. The simulation of the classroom, the establishment of cultural and artistic activities room and science and technology education laboratory.

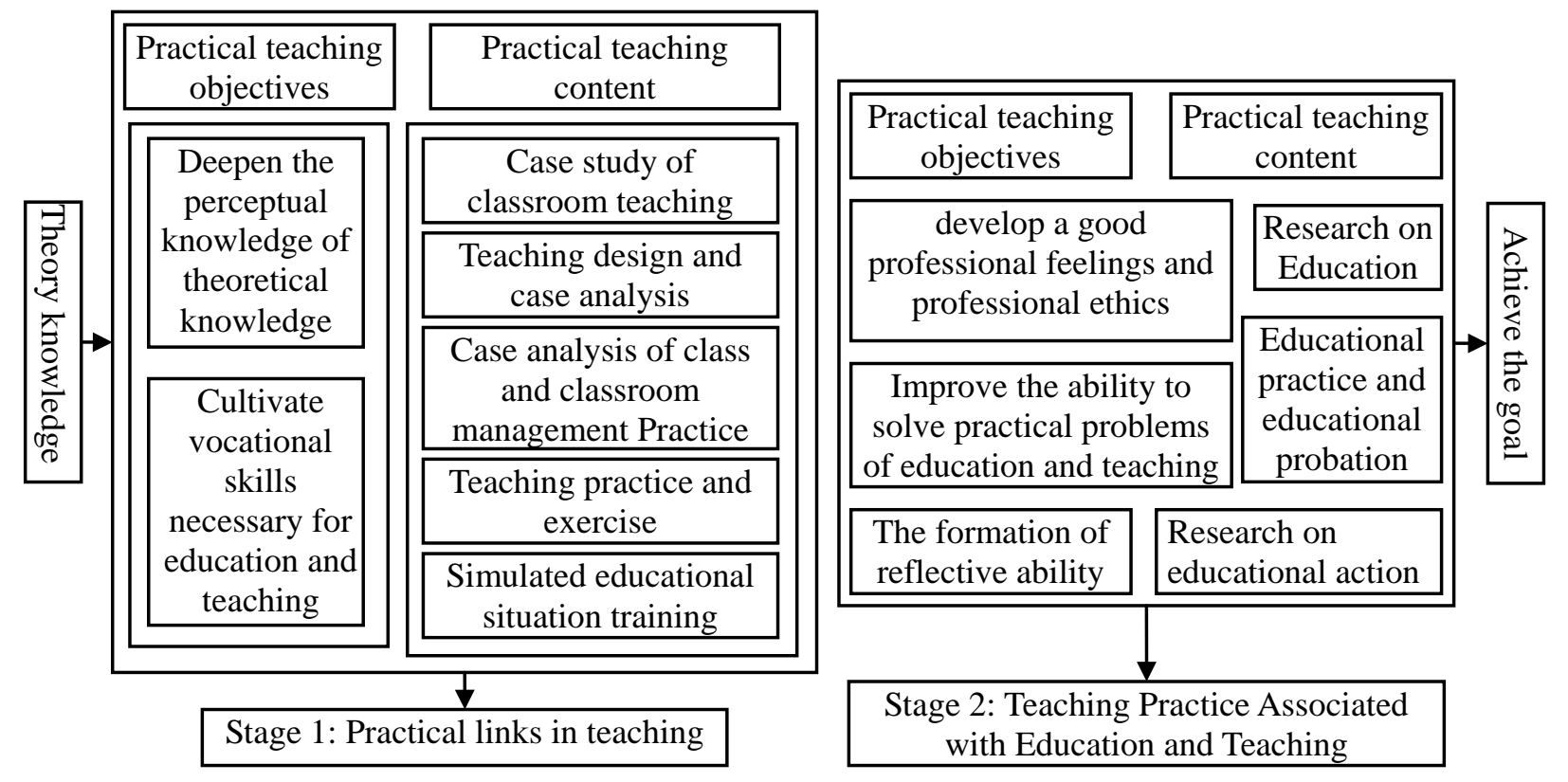

Fig.3. Practical teaching content system

After school, we firmly walk "into the fields, rooted in the grassroots" line, primary school education teachers lead students in-depth basic education to observe the first-line classroom, the use of panoramic teaching, on-site diagnostic teaching, situational teaching and other methods to 
stimulate students to explore the enthusiasm with interest.

\section{Teaching Content and Methods}

(1) Theoretical teaching "case". In the reform of master's degree in primary school education, we gradually establish a theoretical teaching model based on the case database. The basic teaching mode of professional basic course and professional core course should be based on case teaching, and the way of basic theory should be adopted in order to deepen students' understanding and application of basic education theory. [5]

(2) Practical teaching "scene". The teaching process of the scene of the reform, the purpose is to pursue the effectiveness of professional teaching reform and practicality. For the primary school education master's degree students, practical as long as reflected in the teaching to guide students to participate in the teaching of teaching, inquiry teaching, cooperative teaching and other models into the course of teaching, learn to "action research" approach to primary school Teaching practice research, so that students in learning knowledge and theory at the same time, through experience, participation, training their teaching practice ability.

(3) Teaching method "(cooperation) interactive". Under the background of the reform of basic education curriculum, the training of postgraduates in primary education should adhere to the teaching methods such as cooperative teaching and cooperative learning. Based on the goal of cultivating primary and middle school teachers, teachers and students should gradually establish a mechanism for cooperative interaction to improve teaching efficiency and quality.

(4) Teaching (organization) form "exploratory". Similarly, China's basic education reform, the progressive realization of the teaching organization form of inquiry, subject. In view of the reality of classroom teaching reform, the theme of the course topic, subject, has gradually cultivated graduate teaching and research ability. [6]

\section{Practice Base Construction}

Since 2008, with the primary school education undergraduate professional development process, our department has cooperation relationship with Guo He Primary school, Jinzhou Experimental School, Ping He Primary School, Shu Guang Primary School and Chemical Primary School in Huludao and several primary schools into practice base. After several years of coordinated communication and continuous communication, we initially established a benign interaction mechanism with the practice teaching base school.

(1) Primary school education teacher and also part-time base school vice president, responsible for coordinating communication between graduate students and basic school teachers;

(2) The relationship between the professional team and the base school teachers is the learning community, the two sides' responsible, the right, the profit and so on; based on the relationship between equal exchange and cooperation;

(3) The elective courses of primary school teachers may be taught by topical lecturers, principals and class supervisors with relevant qualifications in the form of lectures.

(4) The graduate students of primary school education can find the research object in the form of case study, empirical investigation and so on, through the practice of practicing base practice, post internship and so on, choosing the practical value and pertinent problem.

Adhere to the application of degree thesis, operational, targeted and professional.

The dissertation should be closely related to the actual situation of the current basic education reform, especially the primary school discipline, primary school teachers, primary school principals, primary school management, primary school teacher and so on.

The form of the paper can be special research, research reports, case studies, school-based curriculum development, teaching materials analysis, teaching case design. The degree thesis must be completed by the graduate student independently under the guidance of the instructor. It is divided into several aspects: collecting information, opening report, investigation or experiment, writing, midterm examination, paper review and reply. According to the degree of education and physical education paper template, the text of the word number of not less than 15,000 words. 


\section{Assessment and Evaluation Mechanism}

(1) Academic assessment "refine". Refers to the primary school education, students in the process of academic assessment, based on the individual student education needs, in accordance with the principles of teaching the principles of education, for different vocational level positioning of primary education students and tailor-made for different individuals "modular" curriculum and "panoramic" teaching model. In the theoretical courses, practical courses, professional skills and other aspects of each of the fine assessment, the development of personalized training program.

(2) Academic evaluation "standardization". Based on the "primary school teacher professional standard", the primary school teacher professional degree course is decomposed, the standard is transformed into the knowledge point of the course, and the professional knowledge points are standardized and quantifiable.

\section{Conclusion}

The introduction of the concept of "advanced ability", make up for the lack of practical ability in the traditional education model, and enhance the soft strength training of primary education masters. [8] At the same time, ability-based, employment-oriented, scientific and rational construction of professional curriculum system, break the barriers between the traditional disciplines, avoid disjoint duplication, standardize the disciplines, give full play to the effectiveness of each course. [9] Build the practical ability to cultivate the system, broaden the students 'practice space and vision, improve the social adaptability, enhance the students' confidence in social work, can effectively alleviate the social primary school education students employment pressure.

\section{Acknowledgement}

This work is supported by Postgraduate teaching reform project of Bohai university in 2016: Action research on "ability to advanced" under the primary school education professional master talent training mode reform; Teaching reform project of Bohai university in 2015: Research on evaluation index system construction and action for process teaching of flipped classroom (BDJG-15-YB-B-012);

\section{References}

[1] Hong Ning, Re - understanding Education - Reflections on the Construction of Teachers' Development Schools[J]. Educational Research, 2001(11): 49- 52.

[2] Jun Yang, Xuefan Wang. A Study on the Reform of Practical Teaching Mode in Primary Education [J]. Journal of Bohai University,2013, (01): 105-106.

[3] Weijian Liu, Chuanjin Wang. Introduction to Pre - service Education Practice[M]. Nanjing: Nanjing Normal University Press, 2017:13.

[4] Dequan Zhu, Kesong Lin.On the Reform of Clustering Curriculum Model of Wide and Living Primary Education[J]. Higher Education Research,2011, (1).

[5] Fuquan Huang, Renhong Shen. Primary school education professional module integrated curriculum construction [J]. Course. Teaching material. Teaching method,2002,(9).

[6] Weidong WU. The New Standard of Teacher Education in Germany and Its Implications[J]. Foreign Educational Research,2006,(9).

[7] Chengwen Hong. The latest development of international teacher education quality assurance system [J]. Comparative Education Research,2003, (11).

[8] Yule Jin. The Practice of "Extended Classroom" in Primary Education (undergraduate) [J]. Higher Education Research,2009, (3). 